\title{
A Localizing Circumferential Compression Device Delayed Death After Artificial Eastern Diamondback Rattlesnake Envenomation to the Torso of an Animal Model in a Pilot Study
}

\author{
Jason B. Hack • Babatunde Orogbemi • \\ Jocelyn M. DeGuzman • Kori L. Brewer • \\ William J. Meggs • Dorcas O'Rourke \\ Published online: 27 March 2010 \\ (C) American College of Medical Toxicology 2010
}

\begin{abstract}
Nearly all prior studies to delay onset of systemic toxicity and death after snake bite use a model of distal extremity envenomation. In the first of a series of planned studies using snake venoms with different toxicity profiles, the application of a novel device in a new model of torso envenomation in the setting of Eastern Coral Snake (Micrurus fulvius) venom (a potent neurotoxin) envenomation showed promise by delaying systemic intoxication. In this pilot study, we investigated this novel localizing circumferential compression (LoCC) device's ability to delay onset of life threatening systemic toxicity after Eastern Diamondback Rattlesnake (Crotalus adamanteus) envenomation, a potent hemotoxic and myotoxic venom. With university approval, four juvenile female pigs (22$25 \mathrm{~kg}$ ) were anesthetized, sedated, and intubated but not paralyzed to allow for spontaneous respirations. Each animal was injected subcutaneously with $50 \mathrm{mg}$ of $C$.
\end{abstract}

J. B. Hack • B. Orogbemi · J. M. DeGuzman · K. L. Brewer • W. J. Meggs

Department of Emergency Medicine, Brody School of Medicine, East Carolina University,

Greenville, NC, USA

D. O'Rourke

Department of Comparative Medicine, Brody School of Medicine, East Carolina University,

Greenville, NC, USA

Present Address:

J. B. Hack $(\square)$

Medical Toxicology,

Warren J. Alpert Medical School of Brown University,

Providence, RI, USA

e-mail: jhack@lifespan.org adamanteus venom in identical preselected areas of the trunk. After $1 \mathrm{~min}$, two treatment animals had the LoCC device applied; two control animals had no intervention. Vital signs were recorded every 10 min for the first $2 \mathrm{~h}$ and every $30 \mathrm{~min}$ thereafter. Endpoints included cardiovascular collapse (fatal arrhythmia, loss of mean arterial pressure, or pulse) or respiratory arrest $(<3$ breaths $/ \mathrm{min}$, saturation $<80 \%)$ or survival to $7 \mathrm{~h}$. The pigs in the treatment group reached an endpoint at an average time of $355( \pm 65)$ min compared with control $32( \pm 3.5) \min (p<0.04)$. In this pilot study, the LoCC device significantly delayed onset of systemic symptoms and death after torso envenomation with Eastern Diamondback Rattlesnake venom in this model.

Keywords Snake bite $\cdot$ Novel device $\cdot$ Treatment

\section{Introduction}

In the USA, about 6,700 snake bites are annually reported. Rattlesnake bites make a significant contribution to this number [1-6]. While medical center treatments have been established, out of hospital management of snake bites is less standardized. Therapies currently recommended for distal extremity snake bites include the application of an immobilization technique for the injured area [7-10]. Previously used field methods include tourniquets, ice, venom extraction, and electric shock therapy, but all can cause harm and most are no longer recommended [11-14]. Several studies have shown efficacy of extremity immobilization and lymphatic compression bandages as a way to retard spread of venom as a bridge to definitive medical care [15-19]. No previous studies have examined, charac- 
terized, or developed management strategies for caring for victims of a proximal extremity or torso envenomation. In this pilot, translational research study, we used a swine model for torso envenomations and treated these injuries using a novel localizing circumferential compression (LoCC) device to delay onset of systemic toxicity after artificial Eastern Diamondback Rattlesnake (Crotalus adamanteus) venom injection. We hypothesized that the application of the LoCC device after a torso envenomation with this potent toxin would delay onset of systemic symptoms including respiratory and cardiovascular arrest and death when compared with a nonintervention group.

\section{Materials and Methods}

\section{Study Design}

This pilot study was an unblinded, controlled trial of the LoCC device in a porcine model of artificial torso Eastern Diamondback Rattlesnake (C. adamanteus) envenomations.

Approval was obtained for this protocol from the Institutional Animal Care and Use Committee.

Estimation was made for the fewest number of animals that could be used and still show a statistically significant difference based upon our previous work.

\section{Animal Subjects}

Four juvenile female pigs ranging from 22 to $25 \mathrm{~kg}$ were used. The porcine model was chosen because of the similarity of response to snake venoms as compared to humans $[9,19,20]$.

The pigs were obtained from North Carolina State University and cared for in a manner consistent with standards contained in The Guide for the Care and Use of Laboratory Animals (National Academy Press, 1996). This study was approved by the University's Institutional Animal Care and Use Committee (IACUC). The University animal care and use program is fully accredited by the Association for the Assessment and Accreditation of Laboratory Animal Care, International.

\section{Materials}

Eastern Diamondback Rattlesnake (C. adamanteus) venom (Medtoxin Venom Laboratories, Deland, Florida) was obtained as lyophilized powder and reconstituted with sterile water to $50 \mathrm{mg}$ per $1.5 \mathrm{~mL}$.

The device (Hack, patent pending) consisted of the localizing circumferential compression (LoCC) form and a belt. The belt was composed of a 3-in.-wide elastic strap with D-rings at both ends and a sliding buckle so tension could be incrementally adjusted to the tightness similar to what a sprained ankle would be wrapped. This tension has been shown to be effective in studies describing placement of pressure-immobilization bandages in extremity envenomations [19]. The LoCC form was hand-molded from polymer clay into a hollow, flat, fusiform shape with an internal dimension of $8 \times 5 \times 3 \mathrm{~cm}$ and a hook at each end. The belt was attached to the form by metal D-rings which secured the device circumferentially around the torsoadjustments were made in tension by shortening or lengthening the belt using the sliding buckle as needed depending on animal size (see Fig. 1).

\section{Study Protocol}

The animals were sedated (telazol $5-6 \mathrm{mg} / \mathrm{kg} \mathrm{IM}$ and xylazine $1 \mathrm{mg} / \mathrm{kg} \mathrm{IM}$ ), anesthetized (isoflurane $1-3 \%$ for duration of study), and endotracheally intubated. Neuromuscular blockers were not used to allow for continuous spontaneous respirations. An IV was placed in an ear vein, and an arterial catheter was placed in either a carotid or femoral artery by means of cut down. The pigs were attached to a Hewlett-Packard monitor (model \# 78834c
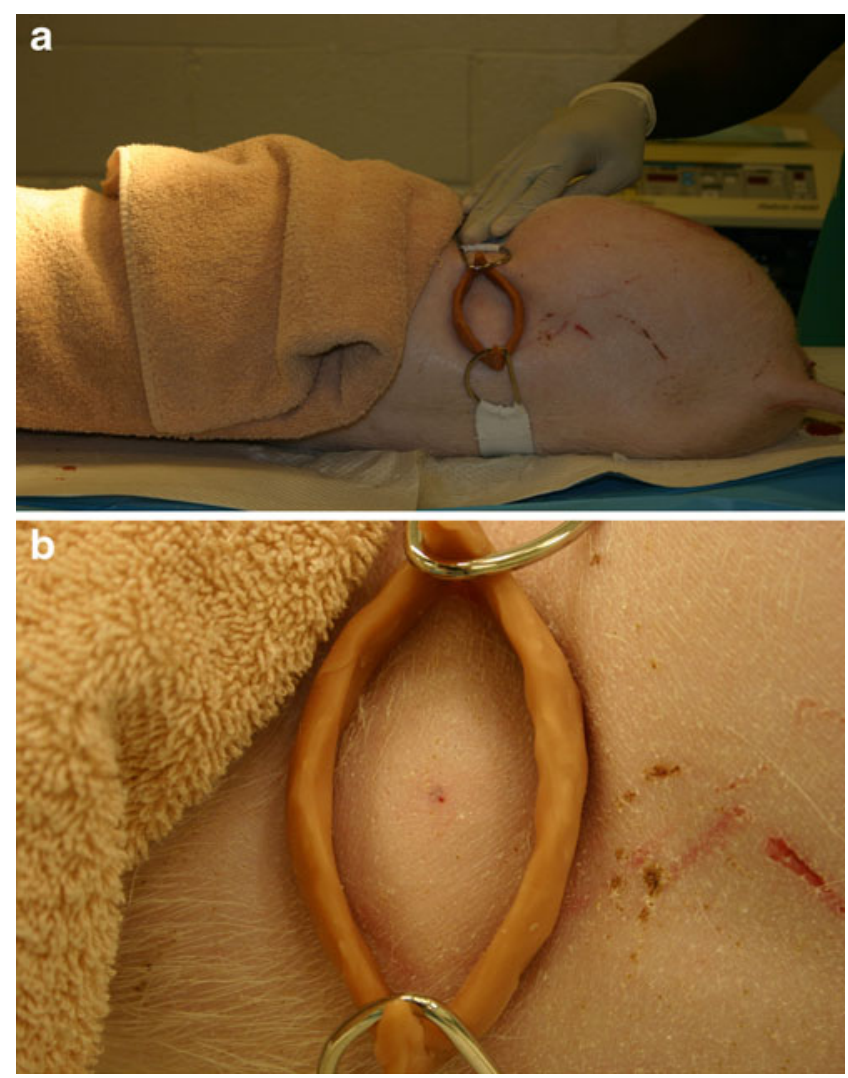

Fig. 1 a Device applied 1 min after injection of rattlesnake venom to torso of swine $\mathbf{b}$ Detail of positioning of LoCC device around venom injection site 
3200 Hillview Ave Palo Alto, Ca) or an Escort Prism (model \#20403 Medical Data Electronics, 12720 Wentworth St., Arleta, Ca) for continuous measurement of arterial blood pressure, pulse, heart rhythm, and pulse oximetry. All the animals were placed in an identical left lateral decubitus position. Hair on the right flank was sheared with clippers. After alcohol prepping, an identical injection site was marked with pen on the skin in all animals.

A 10-min observation period was used to ensure that the animals' heart rate, blood pressure, respiratory rate, and pulse oximetry were normal and stable after instrumentation. Then $50 \mathrm{mg}$ of venom was injected subcutaneously to a depth of $3 \mathrm{~mm}$ using a 25-gauge syringe after aspirating for blood. Treated animals had the application of the LoCC device 1 min after injection. The device was placed around the bite site, and the belt was wrapped around the torso and right hind leg for stability. All LoCC devices were applied by the same operator (Fig. 1). Control animals received no treatment after injection. Vital signs were recorded every $10 \mathrm{~min}$ for the first $2 \mathrm{~h}$ and every $30 \mathrm{~min}$ thereafter.

The primary outcome variables were: (1) time in minutes to onset of systemic toxicity defined as either respiratory failure (respirations $<3$ breaths /min or oxygen saturation $<80 \%$ ), or cardiovascular collapse (loss of blood pressure (mean arterial pressure) or pulse) and (2) survival to $7 \mathrm{~h}$ (420 min).

\section{Data Analysis}

Time to onset of toxicity is reported as the mean \pm SEM and was compared between control and treated groups using a paired $t$ test with $p \leq 0.05$ indicating significance. Survival analysis was performed using the Mantel-Cox test to assess time to death with outcomes represented in a Kaplan-Meier Cumulative survival plot. Power analysis showed that only two animals/group would be necessary to detect a difference in time to onset of toxicity of $120 \mathrm{~min}$ at $p=0.05$ ( $90 \%$ power).

\section{Results}

All four animals survived induction and instrumentation; they all had normalization of their vital signs and were usable for the study. No difficulty was encountered with injection of venom. There were no significant differences in baseline laboratory values between each pig including complete blood count, basic metabolic panel, PT/PTT, and creatinine phosphokinase. There was no difficulty encountered with application of the device around the envenomation site (Fig. 1a, b). The control group had significant difference in time to cardiovascular collapse as indicated by the loss of pulse and mean arterial pressures (Fig. 2a, b). The pigs in the control group had an average time to toxicity of $32.5 \pm$
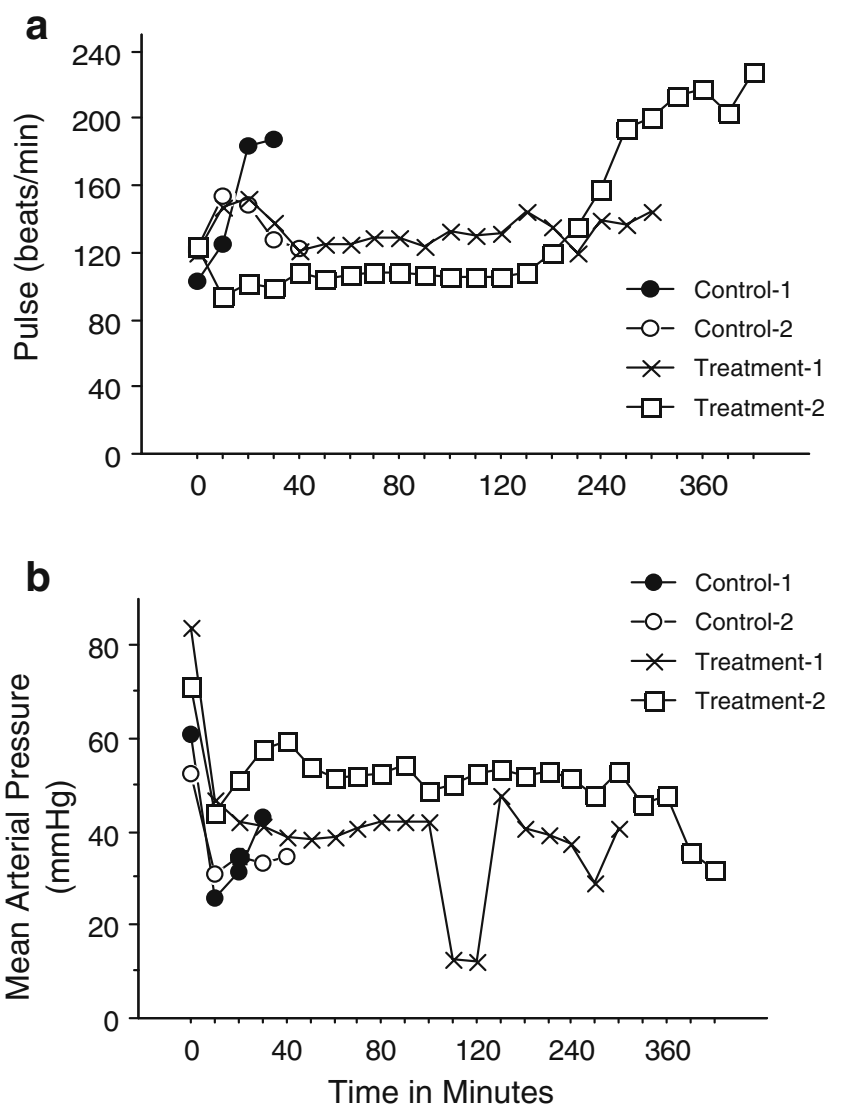

Fig. 2 a Vital signs. Pulse rate during experiment until just prior to cardiovascular collapse. b Mean arterial pressures during experiment until just prior to cardiovascular collapse

$3.5 \mathrm{~min}$, compared to $355 \pm 65.0 \mathrm{~min}$ in the pigs that had the application of the LoCC device $(p<0.03)$. Survival analysis indicated that treated animals had a significant delay to the time of death (Fig. 3; $p=0.04$ ).

Although not formally assessed, several interesting observations were made during the study. Immediately after injection, all animals had myokymia (fine muscle

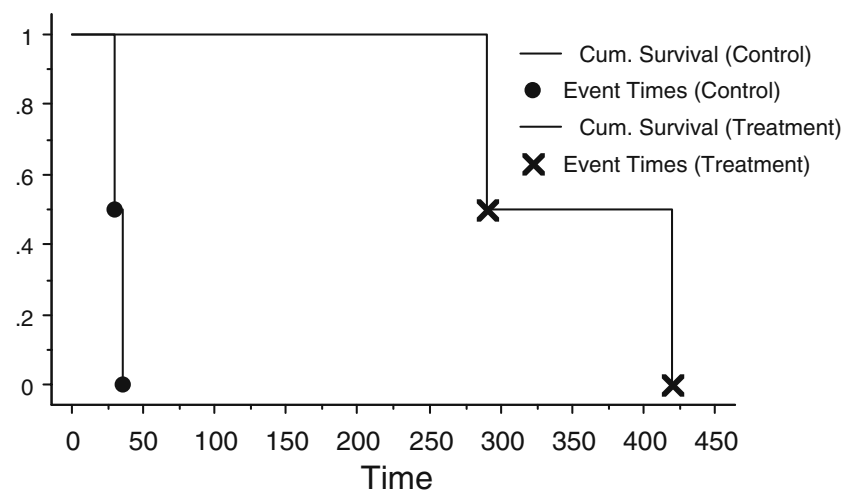

Fig. 3 Survival time. Time endpoint was reached for each animal. The second treatment animal survived to be euthanized at the predetermined study endpoint (420 min) 
tremor) at the site of injection. The control animals had occasional episodes of fasciculation at areas remote from the injection site. The treatment animals, after the application of the LoCC device, had no further episodes of fasciculation distal from the injection site.

Additionally, when the areas under the injection site were examined by gross dissection after each animal was euthanized (approximately $40 \mathrm{~min}$ after injection in the control animals), it appeared that the control animals' area of hemorrhage was much more extensive, wider, and deeper into the muscle layer, when compared with the treatment animals (who were examined with dissection hours after the injection).

\section{Discussion}

Although numerous studies have looked at extremity envenomation, to date there is no literature using a model of torso envenomation. Current recommendations for extremity bites such as immobilization and splinting, compression bandage, or even early application of suction device have not been studied for torso envenomations. Application of a suction device could be limited by presence of hair, difficulty maintaining suction, or some commercial extractors' inability to encompass fang punctures wounds simultaneously [21].

This study used a novel localizing circumferential compression device for Eastern Diamondback Rattlesnake envenomation in the torso of a porcine model. Prior studies showed that extremity immobilization and use of a compression device slowed the spread of venom and delayed the onset of systemic toxicity [15-19]. The delay of onset of systemic symptoms has been shown to be related to the ability to retard lymphatic spread of the venom by applying an extremity compression device [15, 16]. We applied the same concept to the use of a novel circumferential device for torso envenomations. Our result demonstrated a marked difference in time of survival in the group that received the LoCC device compared to the control group.

All pigs had noticeable reduction in blood pressures less than $5 \mathrm{~min}$ after envenomation. The endpoint of respiratory failure occurred in the two controls at 30 and $36 \mathrm{~min}$. One pig in the treatment group reached the endpoint of respiratory failure at $290 \mathrm{~min}$. The second treatment animal reached the endpoint of $420 \mathrm{~min}$ without any signs of systemic toxicity. The control group displayed significant myokymia (fasciculations) after envenomation, consistent with prior evidence that has linked myokymia to these bites and respiratory failure [22, 23].

Although not formally assessed, upon gross dissection of the envenomation areas and surrounding tissue, it appeared that the hemorrhage and area of muscle necrosis were primarily localized to the tissue bounded by the LoCC device, and in the control animals, the area of injury appeared much larger and deeper.

If the findings of our study are borne out in human studies, this technique for field treatment of torso or proximal extremity envenomations would potentially be beneficial for people at risk for sustaining bites in areas where medical help may be delayed. Additionally, this study should reignite interest and funding into techniques that explore new effective wilderness treatment of traditional and nontraditional snake bites; the treatment of which will undoubtedly become ever more important as the ease of travel to exotic locations and the numbers of military personnel in areas far from medical care increases.

\section{Limitations}

Our model of a porcine torso envenomation may not parallel a human torso envenomation and is subject to confirmation by further study. There is only very limited information available on human torso envenomations, and no prior studies have examined an animal model of this. The circumferential elastic band's tightness was not standardized; however, the application of the device in a clinical setting would be done by hand. Although placed by the same operator at a tension presumed to retard lymphatic flow, the device's utility would have been better defined if measured and standardized. It is possible that the effect seen is not secondary to lymphatic compression by the device alone but from the circumferential compression from the elastic band to which the device was attached. In addition, given the fact that the device was applied $1 \mathrm{~min}$ after venom injection, it would be interesting to repeat the study with application of the compression device at different time intervals to see how much time can elapse before efficacy is no longer observed.

\section{References}

1. Litovitz TL, Klein-Schwartz W, White S, Cobaugh DJ, Youniss J, Omslaer JC, Drab A, Benson BE (2001) 2000 annual report of the American Association of Poison Control Centers Toxic Exposure Surveillance System. Am J Emerg Med 19:337-395

2. Litovitz TL, Klein-Schwartz W, Rodgers GC, Cobaugh DJ, Youniss J, Omslaer JC, May ME, Woolf AD, Benson BE (2002) 2001 annual report of the American Association of Poison Control Centers Toxic Exposure Surveillance System. Am J Emerg Med 20:391-452

3. Watson WA, Litovitz TL, Rodgers GC, Klein-Schwartz W, Youniss J, Rose R, Borys D, May ME (2003) 2002 annual report of the American Association of Poison control Centers Toxic Exposure Surveillance System. Am J Emerg Med 21:353-421

4. Watson WA, Litovitz TL, Klein-Schwartz W, Rodgers GC, Youniss J, Reid N, Rouse WG, Rembert RS, Borys D (2004) 
2003 annual report of the American Association of Poison Control Centers Toxic Exposure Surveillance System. Am J Emerg Med 22:335-404

5. Watson WA, Litovitz TL, Rodgers GC, Klein-Schwartz W, Reid N, Youniss J, Flanagan A, Wruk KM (2005) 2004 annual report of the American Association of Poison Control Centers Toxic Exposure Surveillance System. Am J Emerg Med 23:589-666

6. Lai MW, Klein-Schwartz W, Rodgers GC et al (2006) 2005 annual report of the American Association of Poison Control Centers' National Poisoning and Exposure Database. Clinical Toxicology 44:803-932

7. Sutherland SK, Coulter AR, Harris RD (1979) Rationalisation of first-aid measures for elapid snakebite. Lancet 1:183-186

8. Hardy DL Sr, Bush SP (1998) Pressure/immobilization as first aid for venomous snakebite in the United States. Herpetological Review 29:204-208

9. Bush S, Green S, Laack T, Hayes W, Cardwell M, Tanen D (2004) Pressure immobilization delays the mortality and increased intracompartment pressure after artificial intramuscular rattlesnake envenomation in a porcine model. Ann Emerg Med 44:599-604

10. Sutherland SK, Coulter SK (1984) Early management of bites by the eastern diamondback rattlesnake (Crotalus adamanteus): studies in monkeys (Macaca fascicularis). Am J Trop Med Hyg 30:497-500

11. Gill KA (1970) The evaluation of cryotherapy in the treatment of snake envenomization. South Med J 63:552-556

12. Bush SP, Hegewald KG, Green SM et al (2000) Effects of a negative pressure venom extraction device (Extractor) on local tissue injury after artificial rattlesnake envenomation in a porcine model. Wilderness Environ Med 11(3):180-188

13. Dart RC, Gustafson RA (1991) Failure of electric shock treatment for rattlesnake envenomation. Ann Emerg Med 20:659-661

14. Johnson EK, Kardong KV, Mackessy SP (1987) Electric shocks are ineffective in treatment of lethal effects of rattlesnake envenomation in mice. Toxicon 25:1347-1349
15. Tun-Pe, Muang-Muang-Thwin, Myint-Myint-Than, Aye-Aye-Myint, Kyaw-Myint, Thein Than (1994) The efficacy of compression immobilization technique in retarding spread of radiolabeled Russell's viper venom in Rhesus monkeys and "mock venom" NaI131 in human volunteers. Southeast Asian J Trop Med Public Health 25:349-353

16. Howarth DM, Southee AE, Whyte IM (1994) Lymphatic flow rates and first aid in simulated peripheral snake or spider envenomation. Med J Aust 161:695-700

17. Anker RL, Straffon WG, Loiselle DS, Anker KM (1983) Snakebite: comparison of three methods designed to delay uptake of "mock venom. Aust Fam Physician 12:365-368

18. Tun-Pe, Sann-Mya, Aye-Aye Myint, NuNu Aung, Khin Aye Kyu, OO Tin (2000) Field trial of efficacy of local compression immobilization first-aid technique in Russell's viper (Daboia russelii siamensis) bite patients. Southeast Asian J Trop Med Public Health 31:346-348

19. German BT, Hack JB, Brewer K, Meggs WJ (2005) Pressureimmobilization bandages delay toxicity in a porcine model of eastern coral snake (Micrurus fulvius fulvius) envenomation. Ann Emerg Med 45:603-608

20. Tanen D, Danish DC, Grice GA, Riffenburgh RH, Clark RF (2004) Fasciotomy worsens the amount of myonecrosis in a porcine model of crotaline envenomation. Ann Emerg Med 44:99-104

21. Zamudio KR, Hardy DL Sr, Martins M, Greene HW (2000) Fang tip spread, puncture distance, and suction for snake bite. Toxicon 38:723-728

22. Vohra R, Cantrell FL, Williams SR (2008) Fasciculations after rattlesnake envenomations: a retrospective statewide poison control system study. Clinical Tox 46:117-121

23. LoVecchio F, Pizon AF, Wallace KL, Kunkel DB (2005) Myokymia after snake envenomation in Arizona. Wilderness Environ Med 16:116-117 